\title{
Amalgamation of Culture and Cuisines: Indian Culinary Culture
}

\author{
Anishika Kapoor
}

Amity Institute of English Studies and Research, Amity University, Noida

Received: 26 Jun 2021; Received in revised form: 25 Jul 2021; Accepted: 06 Aug 2021; Available online: 13 Aug 2021

C2021 The Author(s). Published by Infogain Publication. This is an open access article under the CC BY license

(https://creativecommons.org/licenses/by/4.0/).

\begin{abstract}
As Mark Twain once said, "In religion all other countries are paupers; India is the only millionaire". Food is an excellent manifestation of who we are as people. It defines our identities, customs, traditions. It reflects who we are, the flavors of cooking that have been passed down through generations. Food is culture and India can be proud of its illustrious culinary heritage.
\end{abstract}

Keywords-Cultural Influences, Identity, Indian Culinary Culture, Spice-Route

\section{INTRODUCTION}

As Harvard anthropologist Theodore Bestor said, "the culinary imagination is a way a culture conceptualizes and imagines food."There are thousands of castes and tribes in India, as well as twenty-two official languages and hundreds of dialects, six major world religions, and numerous ethnic and linguistic groups. Food in India is an identity marker of caste, class, family, kinship, tribe affiliation, lineage, religiosity, ethnicity, and ever more secular group identification. Understanding the Indian social landscape, as well as the relationships, emotions, statuses, and transactions of people within it, requires an understanding of how people eat, what they eat, with whom, when, and why they eat.

Food offers a window into both veiled and visible facets of Indian society, as well as the nuances of identity and contact with other parts of the world. Indian cuisine dates back over 5000 years. Each region has its own traditions, religions, and culture thatinfluences its food. Indian food has been influenced by European, Chinese, Persians and many more. The common thread throughout the centuries remains the distinct mixing of spices that invariably gave Indian cuisine its flavor and aroma. Colleen Taylor Sen, in her book Feasts and Fasts: A History of Food in India, sets out to document Indian food through history. She follows the history of Indian food through the Vedas, noting that alcohol was forbidden, but other intoxicants like som ras, were used for religious rites. The book has similar interesting titbits focusing primarily on spices that Sen sees as the connecting thread between foods in their vast variety. The author gives us a complete overview of the influences of contemporary Indian cuisine following history through the empires and religions.

Indian food is often thought of as exotic cuisine. K.T. Achaya's Indian Food: A Historical Companion, is a treasure trove of intriguing knowledge on and about Indian food and everything else related to it. The dominant flavors of the book are historical and describe the vast array of cuisines, foodstuffs, and dishes that belong to the term 'Indian Food' collectively. Food is an integral part of the Indian tradition, that can be endured in everyday life, particularly during the festive seasons with all the rituals taking place. With the culinary cycles, festivals, or sacred seasons of the year that are ubiquitous with sacrifices to the gods and feasting on specific foods. Food is a way for Indians to socialize, gather with family, relatives, and friends. Everyday meals are sit down affairs consisting of two or three main course dishes, varied accompaniments such as homemade chutneys and pickles, rice and roti along with desserts. Indian cuisine play, a distinctive role, thus dividing it into four parts, namely the North, the South, the East and the West. The diversity is fused in Indian cuisine with the various use of spices that are an integral part of the preparation of foods that help to make mouthwatering dishes. The food ranges from very simple 
vegetarian to exotic non-vegetarian dishes layered with texture and flavor, which are concocted with great care and techniques no matter how simple or complex an assortment is. Given this diversity, it is fascinating to discover what made Indian food indigenous and how it came about. With his book A Culinary Tour of India, Yogesh Singh helps us decipher the development of Indian food by highlighting the finer elements of culinary styles and systems, food trends and customs, basic diets and a plethora of dishes. Additionally, dedicated to the various regional cuisines of India and highlighting the trends and culinary details of the Indian cuisine, such as spices, various gravies, breads, beverages, sweets, biryani and pulao, and particularly kitchen appliances at length. It illustrates the shape of beautiful Indian cuisine, the impact of different religions and a brief description of festive mouthwatering food, and explores the relationship between food and Ayurveda.

India is a country of astonishing geographical diversity, with virtually every climate imaginable: the frigid peaks of the Himalayas, the cedar woodlands of Kashmir, the lush green forests of Kerala, the bone-dry deserts of Rajasthan and the flood plains of Bay of Bengal, as well as 7,500 miles of coastline and ten major river systems. In India as elsewhere, food culture is influenced by the climate, land and the access of natural resources. The food system emphasizes on eating food 'in season', such as mangrove and local greens, pumpkins during the rainy months of the monsoon and root vegetables during the winter months. RatnaRajaiah, recollects all of these facts with her book, Secrets of Health from the Indian Kitchen, through which she pays an ode to the ingredients and recipes that the country has forgotten.

K.T. Achaya's, The Story of our Food takes us on a historical journey of the origins of our food and our ancestors, and how the invasion over India affected our food culture. The author begins by describing our ancestry and ancient languages that were enunciated, in India such as Munda, Sanskrit, and Tamil, and certain English words like Rice and curry, which originated and got their name from Tamil words like Arisi and Kari. He then goes on to explain how weeds became food grains and how man began cultivating using these weeds bearing food grains. He also discusses India's indigenous products. Food is an excellent manifestation of who we as people are. It elucidates our identities, customs and traditions. It mirrors who we are, the flavors of cooking that have been passed down through generations. Food is culture, and India can be proud of its illustrious culinary heritage.

The spice trade has spawned a variety of cuisines, and history has played a significant role in their development. Delving deep, it is surprising to know that various factors contribute in creating a cuisine. Religion, cooking techniques, family traditions, new ingredients even the smallest change can result in a completely different flavor. And each family would add their own unique spin on things, causing things to shift slightly. Food culture evolves not only locally, but also across borders. With her book, Eating with History: Ancient TradeInfluenced Cuisines of Kerala Tanya Abraham takes the reader on the journey of the discovery of the famous spice route which opened new gates for the new cultures to enter India and influence its cuisines with their own. It chronicles the culinary journey of growing up in a society influenced by multiple cuisines and belonging to parents of two different Christian communities. The book contains a little more than 100 recipes, the majority of these were passed down through families with influences from the Paradesi and Malabari sects, Syrian Christians, Muslims, Anglo-Indians, Latin Catholics, among others. The book chronicles the evolution of Kerala cuisine, tracing the changes that existing dishes underwent and, as a result the emergence of new cuisines. Ships traveling across oceans to gather spices from Kerala brought food, cultures and religions with them, enabling the creation of new cuisines. Thus, showcasing how new cultural aspects of heritage sculpted, and explains that our history is intricately locked in food.

\section{INDIGENOUS POT'S HISTORICAL JOURNEY}

For thousands of years, food plants have made their way to India to be embraced, adapted, nurtured, and cherished here. Visitors to our country from antiquity, whether Greek or Chinese, Arab or European, have expressed their perplexity at the variety and abundance of food found in India. From the Aryan descendants to the Mughal culture, to Europeans and South Americans, and many other cultural influences, there has been a significant shift in the food preparation, adding new dimensions to Indian cuisine. The reason for the unique flourishing of communities for centuries is owed to the rulers of that time, who welcomed the foreign settlements, for the main reason of economic gain. The ruling kings provided land and allowed new nationalities to establish communities, as well as marry native women and raise families (Abraham22). India has been called a universe, not a country. It is the second most populous country in the world after China and the seventh largest in area; no other country has such a diversity of climate and soil, race and language, religion and sect, tribe, caste and class, custom, and cuisine. In its multitude of languages and ethnic groups, India is sometimes compared to Europe. As Mark 
Twain said, "In religion all other countries are paupers; India is the only millionaire" (Taylor7).

During the Indus Valley Civilization, which is the oldest civilization, came the cultivation of sesame and eggplant. As for the humble eggplant which was mocked by James Kirkpatrick, the British resident at the court of the nizams in Hyderabad, the vegetable has as mystical a status as in Turkish or Middle Eastern cuisine. Given its long availability as an indigenous vegetable, its importance in Indian cuisine cannot be overstated (Banerji168). By 3000 BCE, other agricultural produce like turmeric, cardamom, black pepper and mustard were grown. Agriculture evolved gradually, and with it came a blending of ingredients, giving rise to new flavors and cooking styles. As Tanya Abraham shares in her book, Eating with History: Ancient Trade-Influenced Cuisines of Kerala, when the Portuguese arrived at Kerala, they brought along new food products, and also augmented the cultivation of spices such as, ginger, pepper, cinnamon, cardamom, which had great demand in Europe (Abraham25). Fruits and plants with unprocessed sweeteners such as honey became the most prominent food products with the advent of Ayurveda. The Rigveda also mentions the use of honey, during the time of the Aryans. It consists a description of a unique drink made by the concoction of honey, curd, and ghee called "madhuparaka", which was served to the guest as a mark of hospitality (Singh7). Honey is the most common, oldest, and most ancient sweetener. The product derived from small bees was superior to that derived from large bees, according to the Rigveda (Singh8). Many think that the Ayurvedic cooking tradition, which is holistic in cooking, provides the basis for the concept that all we eat affects both our body and mind, so the food is natural and equilibrated.

India was largely a vegetarian state for a long time due to the Buddhist ahimsa preaching, and Hindu's faith in Karma, (which induced them not to harm other living organisms). Like the rest of India, people of Kerala also learned to adapt to the produce of the country, heavily dependent on the agriculture and the forests. The influence of conquerors from afar changed eating patterns and influenced cooking in countless ways (Abraham23-24). Indeed, the Buddhists brought with them new cooking techniques, as well as new ways to combine various fruits and dry fruits with milk, milk products, cereals, pulses to create delectable dishes.

The Mughals also pursued fervently the fine varieties of mangoes developed by the Portuguese through grafting techniques. The Ain-i-Akbari written in 1590 by Abul Fazl lists 35 fruits, such as, watermelon, peaches, almonds, pistachios, pomegranates, etc. which were grown in the imperial gardens, are everywhere to be found.
The Aryans brought agricultural knowledge with them, and the Vedic civilization evoloved into an agricultural, pastoral and philosophical civilization. The Aryans established the agricultural pattern of food production that continues to exist and practiced in India today. During the Aryan civilization, between $1700 \mathrm{BC}$ to $800 \mathrm{BC}$ the four Vedas documented the rich and detailed Aryan food and drink and the culture of that era. The Aryans were excellent cultivators, and as a result, they were experts in growing auxiliary foods such as pumpkin, gourds and mangoes. Peppers and cardamoms came from South India, and asafoetida from Afghanistan. Few more fruits and vegetables were described and recorded in subsequent Vedas, including bael, ber, amla, Indian fig, jackfruit, banana, jamun, coconut, palm, phalsa, and several other citrus species (Singh7). The Aryans were people with great taste with excellent dining habits and hence, have enjoyed fruit beverages as refreshing drinks, and consumed a variety of meat dishes and even alcoholic drinks. The Aryans primarily ate barley. It was fried and eaten in a variety of ways. It was consumed as gheedipped cakes or as sweet cakes called apupas (now known as malpua), made from barley flour boiled in water or fried in ghee and then dipped in honey. In very early Sanskrit writings, barley is referred to as yava, and it was the main source of food at the time. It is no longer a popular food grain, having been supplanted by rice and wheat (Achaya21).

Despite the fact that barley was their first food, rice quickly became the most important staple food. Sowing, irrigation, seeding, transplanting, weeding, watering, protecting from birds such as parrots, defense against pests such as rats, locusts, borers, and other vermin, and final reaping and threshing were all given equal attention. The Aryans recognized and practiced the need for land rest after growing a single crop.Crop rotation and seasonal sowing were thoroughly understood.Rice was planted during the rainy season and harvested at the start of the summer the following year.Lentils, beans and peas were then harvested during the spring, while barley, wheat and linseed were seeded in winter and harvested before summer began. Rice was cooked with either water or milk, and consumed with additions like curd, ghee, sesame seeds or meats.

Rice is the preferred staple food of South India, whereas wheat is today preferred in the north. But what is noteworthy is the fact, that rice has been developed in northern and eastern India and has entered South India at a somewhat later time, according to archeological discoveries. It's surprising that 100,000 rice varieties exist only in India, and twice as many in the world(Achaya 2223). 
Food was not only a source of sustenance and nourishment for the body in Aryan belief, but it was also a part of the cosmic universal moral cycle. The history of Indian cuisine cannot be complete unless foods from the epic period, the Mughals, and the European periods are discussed.

\section{THE MINGLING AFFAIR OF SPICES AND INGREDIENTS}

Foreign visitors have been awestruck by the country's agricultural bounty since antiquity. Lentils such as urad, mung, and masur dal, millet, aubergines, pumpkins, melons, and gourds, mangoes, jackfruit, citrus fruit, ginger, turmeric, tamarind, and black and long pepper are all indigenous to India. India is also home to domesticated chickens. These foodstuffs are still an important part of many Indian's diets today. It has served as the center of a vast network of land and sea trade routes since the Indus Valley Civilization in the third millennium BCE that introduced the plant, ingredients, dishes and cooking techniques to and from Afghanistan, Persia, China, the Middle East, and many more. Plants like tomatoes, pineapple, cashews, potatoes, chilies have beenbrought by Europeans in the Western hemisphere and elsewhere. "All these, added layer upon layer to what, paraphrasing Nehru, we might call the palimpsest of Indian cuisine, on which no layer ever hides or erases what has gone before" (Taylor8).

Massive demand for spices, particularly black pepper, drove a train of conquerors to India's shores. New religions, new identities and new ways of life came into being through trade. The most powerful influence came from foreign rulers who established themselves in ancient Indian port towns. Their prolonged stay gave way to open mingling with the natives and blending the flavors of the native produce with their own. "The blend of cultures also signified a blend of cuisines in which local spices blend with foreign flavors. The spice trade marked the beginning of this new adventure" (Abraham24). Spices were shipped from the hills of Malabar in Kerala to Arabia, from where they were then transported to Egypt and Mesopotamia. Not only were these spices the foundation of Indian cooking, but they also became essential ingredients in many other cuisines around the world.

In the $15^{\text {th }}$ century, the Portuguese arrived and with them came potato, tomatoes, chilies, cashew nuts, guava, papaya and pineapple. In India, they introduced approximately 300 plants. Fruits like custard apple was brought from South America and mosambi, member of the orange family came from Mozambique, hence the name. "The fruit was highly regarded by Portuguese seafarers after it was discovered that eating it cured dying sailors of scurvy, an illness they encountered on their voyages" (Abraham25). Vinegar was the most influential of the numerous food ingredients introduced by the Portuguese. Despite the fact that vinegar had been produced in India prior to the arrival of the Portuguese, it was they who first used it in cooking. Portuguese majorly used vinegar to preserve salted meats with paprika and garlic which were stored in barrels to be taken on the ships for their voyages to lands afar. Red chili peppers are yet another introduction that has significantly altered cooking. "A whole new flavor was born to meat and fish curries, using red chili peppers" (Abraham28). Not only food habits but eating habits also underwent change. Banana leaves were replaced by utensils of porcelain, and dining areas transitioned from the kitchen floors to table and chairs in a designated dining area. Utensils like Chinese wok, known as "cheenachati" and honey-filled Chinese urns were shipped to Kerala and replenished with pepper and other spices in exchange. The Portuguese are credited with "puttu" the steamed rice cake, which is one of Kerala's most popular staples. "Once used to feed a large number of its army on ships, it is now eaten with a variety of curries throughout Kerala, primarily as a breakfast staple" (Abraham34).

In 1653, the Dutch invaded Cochin, with the intention of eradicating all Portuguese influence.Street names were changed from Portuguese to Dutch, and many buildings, houses, and libraries were demolished; however, they were unable to erase the food and Catholicism.Brudher and Potato cutlets, commonly consumed at places like Fort Cochin, have remained among the few Dutch cuisines.After the Dutch, at the beginning of the 19th century, English people established their establishments and expanded their political interests all over the country.Only a few could afford whisky, which was introduced by the British.Tea was originally brought to India by the Chinese, but it was popularized in Indian culture by the British.However, it was altered by the addition of milk, sugar, and other condiments, resulting in new tea flavors. The coffee is then brought in by the Arabs and transformed later into a milk and sugar sweet version.

A whole new technology with new ingredients was initiated in Central and Northern India, with conquerors coming from Persia, Arabia.Food became more elaborate, with rich dishes and the inclusion of apricots, plums, and pistachios in the cooking.It was followed by meat as a powerful food item. When Muslim traders from the Middle East arrived in Kerala in search of spices, they brought Islam with them. The spice trade was managed by the Arab merchants in Kerala for a long time.Biryani is 
another specialty, with a recipe unique to India.Biryani from Malabar has a distinct flavor that has traveled down through generations by incorporating Arab traditions and blending them with local ingredients.The Arabs also introduced the use of dates in cooking and grilling.

Food gained prominence in people's lives as cultures and traditions flourished in the state.Much influenced by traditions, religion and trade, a wide range of cuisines has emerged.In kitchens, recipes produced from innovative ideas and new ingredients are married to make unique and distinctive flavors.These flavors differed from one community to the next, and even between households.Food became inextricably linked to people's lives and became an inevitable part of life.The one common component that has strongly founded their presence and that has shaped the evolution of cuisines and has distinct features is a tale that calls for safekeeping to think that spices have led to new religions and customs in India.Both for history and the remembrance of those who have brought new tastes to life, which continue to have a great global history.

\section{THE GASTRONOMIC FUSION}

India is a land where the past and the present collide, where nearly every ingredient is grown and contributes to the creation of Indian cuisine.The involvement of people from all over the world has diversified its cooking culture, elevating it to a new level.Despite the different influences that several leaders, invaders, and travelers have brought to the country, Indian cuisine never lost its identity but has become more elaborate, and richer with the assimilation of innumerable influences.India's cuisine is so varied that it has made the world's cooking a significant and unknown mark.The beauty and mystery of India captured people's imagination from far-flung shores for thousands of years and lured them into the coasts.

India has begun adapting and re-inventing its food with colonialization and globalization, such as putting chicken tikka masala as a topping on pizza, and on the other hand, making an exclusively garlic, onion, and eggs - freeversion that the observant Jains can eat (Banerji 324) or the adoption of a standard South Indian dosa as Pan-Indian fast food, particularly among working class (Banerji 72).

Fusion was seen not only in food, as well as in communities. With the arrival in India of different cultures such as Portugal, British, the Netherlands and French, the aboriginal communities of India married and the children born out of their union, were known as 'Anglo-Indians', who followed the British way of life and perpetuated in an Indian context the incongruity of western life.They were regarded as ostentatious, denying their Indian ancestry in order to persuade their British masters.Despite adopting the British way of cooking and eating, they have also made innovative use of ingredients sourced from the land that has served as their physical, if not always spiritual, home (Banerji 100).The Anglo-Indians also pioneered the idea of 'tiffin.'It was a snack-like meal that was typically consumed around midday.The Tiffin of the Anglo-Indians were often residue of roast meats restored like pie or meatballs, spiced by a range of chutney and delicacies (Banerji 102).

It is often easily overlooked, that the arrival of the Muslims was the first significant external influence on Indian cooking and food, radically reshaping. The highend, Islamic imperial cuisine of country was born inthe heart of the country, Delhi, and became exquisitely refined, almost overblown, with two distinctive scions: Lucknow and Hyderabad.One can pick up the aromas of pilaf, biryanis and koftas in the crowded maze of Old Delhi and many other dishes which came from Muslims, enriched by the spices and flavors. The genuine origins of the well-created biryani or pilaf are the products of many influences in today's world.Pilaf was made from rice, minced meat, tons of ghee and seasonings, including onions, peppers, ginger, cumin seeds, cardamom and cloves, as described in his famous Ain-i-Akbari by Abul Fazl. Another pilaf, called Navratan was created in honor of the nine great intellectuals at the Emperor Akbar's court. As rice was the main ingredient for the creation of any pilaf, amongst the rice cultivations in ancient and medieval India, the 'Shali' rice strains were grown over a wide range of terrain and were soft and fluffy when cooked, even while the grains remained entirely separate ideally suited for pilafs. (Banerji 138). Apart from the spices, in the Mughal imperial cuisine, cooks used dried fruits in meat and rice dishes, as a custom that is inherent from Iranian and Turkish culinary practices. "Subsequently, the Mughal chefs adapted the cooking style of the Europeans, especially the Portuguese, who brought in various fruits and vegetables from the New World"(Banerji 139). The Punjabi dhabas food menu in Delhi offers a variety of breads and kebabs that remind people of the coarse Northwest Frontier (a region now in Pakistan), meats, fish and vegetables are all luxuriant with oil and ghee.The sauces in meat are rich lacquered in yogurt, cream or pounded nuts, that all were part of the Islamic Indian cuisine for centuries, or tomatoes introduced by Europeans and popularized by Britishers. Avadh's royal cuisine was undeniably made up by the diversity of the pilafs and biryanis that the nawabs inherited from the courts of Mughal and improved with an extravagant and unique touch.In addition to nuts, raisins and other kinds of dried fruit, those rice dishes also have 
edible silver and gold.'The names of the various pilafs indicate the artistry which has been developed-pearl, garden, cuckoo, jasmine and light.The pearls have been made from equal parts of silver and gold foil with yolks of egg, and have been filled into a chicken gullet that has been purified and ready for cooking.The chicken was cooked for some time in the oven and then sliced and taken out. Like natural pearls, the yolk and the foil were perfectly shaped.Before serving they were then added to the pilaf" (Banerji 157).The British 'meat and potato' penchant also visited the Nawab plate.The potato was liberally added to the biryanis and to the gravy dishes as a supplement to reduce meat costs.In Calcutta, when Biryani are made in Avadh style, the tradition continues to prevail (Banerji 160).Whereas Hyderabad's Muslim cuisine has a strongly southern identity.In addition to the well-known pilafs and meat dishes, vegetarian cuisine is also flary and naive.The flavors of mustard seeds, Kari and ghungura leaves, hot chilies, peanuts, tamarind and coconut milk merge into an aromatic entity which is found nowhere else. The cuisine of Hyderabad is multifaceted. Dalcha is one such instance. Originally made with two types of dal, toor and chana, cooked, pureed, and seasoned with ghee, mustard seeds, and curry leaves.An epitome of sweet and sour flavors is added through brown sugar and tamarind. "its compliance can be exemplified by its numerous manifestations. For seasonal flavors, dalcha may be accompanied by different types of vegetables, or even meats"(Banerji 167).

The ice creams that are served today throughout India are the result of East-West contact.As Chitrita Banerji states in her book, modern ice cream is a culmination of the medieval cuisine tradition, which gave India the kulfi that the Mughals either had brought in or developed in their former habitats in response to the prickly heat of the Ganges.The conical-shaped vessel in which a portion of khoa is frozen gave rise to the name "kulfi."During the Mughal era, it was frozen with an icesalt mixture (Banerji 172-173).Contrary to the Anjeer ka roll, brought into the Nizam family by a Turkish princess a hundred years ago, the ice cream is not related to Nizams and Nawabs(Banerji 174).

In a cosmopolitan city like Bombay, which, "like New York, Bombay is a city where local, national and international cuisines fuse forever into something mindboggling", unlike all of India, a mix of culinary traditions is taking place on a far bigger scale (Banerji 233). Seafood is cooked in different ways and dabbawallas maintain an unblemished record that homemade food is delivered without delay to the citizens of the city of dreams.The East Indian Catholics of Bombay have been transformed into a vulnerable community overtime, disruption in families, inter-caste weddings.Eastern Indian food is, like the cuisines of Goa, Mangalore, Cochin, and Calcutta, a culmination of the exchange of two religions and two races."The authenticity of the community can only be maintained if people are encouraged to study and present to the world the history of the community" (Banerji 236). A variety of sweets and desserts and the combination of a wide variety of spices, sun-dried, roasted, powdered and bottled, form two distinctive features of this cuisine.East Indian food is never stingy hot like some chili laden dishes from Goa or southern states; it is subtly flavorful, the spiciness mitigated by a strong European influence.Tea is another influence that has become an inextricably linked part of our lives.A tea center in Bombay that the government had previously openedis now private.Its menu includes strange and exotic fusions of tea like Hot Buttered Apple Tea, Thai Chai, Rose petal Tea, Yogic Assam Tea and even Mango Chai (iced), with regulars like the Darjeeling, Assam and Nilgiri tea. The food prepared by the East Indians for weddings and Christmas is a fusion of ingredients as described by Chef Swamy Fernandes, who is partly East Indian and author of Enduring Flavors: In Appreciation of East Indian Cuisine. For festive meals, particularly Christmas dinner, East Indians like Goans, glory in their pork vindaloo (again a Portuguese adaptation) and sorpotel. Other specialties include whole roasted suckling pig, duck indad seasoned with Kashmiri red chilies, and small fugeas, which are fried rolls made with flour, coconut milk, sugar, toddy, and a bit of cottage cheese.The Parsi Community, excellent food expertise and a perfect combination of Persian and Gujarati culinary patterns are another thriving community.Their food is represented by a distinct and typical flavor as well as a simple taste (Singh 208). Curry plays a vital role in this cuisine, usually eaten with rice. Ras is another distinct Parsi cuisine, and the only distinction between curry and ras is the use of coconut in the preparation of curries. The people of this community love meat and their cuisine is determined by the Iranian cooking style.They have embedded Indian cuisine in their food culture, shaping an innovative food culture.As Banerji shares an, anecdote of her visit to her Parsi friend'shome for dinner, "Parsi imagination- a combination of East and West. A large serving dish of pilaf sat next to a plate of plain chapattis; crêpes with a vegetable and fish filling were covered in a white sauce. A fiery preparation of sauteed whole okra and a magnificent rawas stuffed with spices and roasted whole" (Banerji 232).

India embraces new trends and foods with equal zeal, devouring both the old and the new with zeal.In her book Eating India: Exploring a Nation's Cuisine, Chitrita 
Banerji writes that India has taught her that authenticity is a myth, that fusion is more than just a restaurant fad, and that tradition lives because it is constantly retouched.The spirit of this land cannot remain stalled for a long time by even the weight of millennia's history, for dark and dull eras, but eventually the strong Indian sun fights against it with light and energy.Food in India has always been and continues to be fusion, albeit an incomplete fusion.

\section{CONCLUSION}

The country was overwhelmed with people who were blessed with refined epicurean senses in all ages, and it helped to develop and build up this endearing cuisine with amazing gourmet perspectives and fundamentals.India is divided into 29 states, each with its own cuisine that reflects distinct peculiarities of ingredient cultivation and availability, climatic conditions, cooking styles, eating habits, specialty dishes, and varied culture.Nevertheless, its cuisine has been documented at a limited periphery with such vividness, complexity and shine.Indian cuisine has an ambrosial and nectarous flavor.No one can stay without being enchanted by the magic, flavor, charm, and taste that it possesses.It is the sun's cooking pot. The resumption process now entails a rejuvenation of specific dishes, the rediscovery of lost cuisines and their creation, as well as a taste for the dishes on the world stage, from sophisticated French or Italian meals to the pleasures of Southeast Asia and China, up to a fast -food menu of the West, that transcends language and culture.In its very ancient times India has been involved in the world food economy, adopting, absorbing and exporting its own food products and ideas, ingredients, dishes and techniques from virtually every part of the globe, such as Central Asia, the Middle East, Persia, China, South-East Asia, the Western Hemisphere, Europe.This exchange has become even more pronounced in the twenty-first century, as people travel freely across continents and culinary boundaries dissolve.Indian food, in its various forms, has evolved into a global cuisine.One reason for that is the increasing awareness of the virtues of conventional diets, in particular the low meat consumption, the myriad of fruit and vegetables, the central importance of grains and the use of spices, whose medical advantages has been demonstrated by science.Vegetarianism, perhaps India's greatest gift to the world, is gaining popularity for ethical, humane, and health reasons.A preference for spicier 'hotter' food was identified by food professionals as one of the main consuming trends of the 21 st century.Almost everyone in the suburbs and towns today has their own Indian grocers, while indigenous products are also on shelves in most supermarkets and at home, migrants seem to be combining
Indian with Western eating patterns.Cooking books have promoted global cuisine exchanges as volumes of various recipes come on the shelves of bookshops across the Subcontinent from various Indian communities, from the Caribbean to South Africa.This latest injection of foreign influences pursues the fusion process through the introduction of new cooking techniques and new ingredients that have given Indian food its vitality for many centuries and made it one of the most, fine cuisines in the globe.

\section{REFERENCES}

[1] Collingham, Lizzie. (2006).Curry:A Tale of Cooks and Conquerors, Oxford University Press

[2] Shankar, Shylashri.(2020).Turmeric Nation: A Passage Through India's Tastes, Speaking Tiger Books LLP

[3] Sen, Colleen Taylor. (2016).Feasts and Fasts: A History of Food in India, Reaktion Books

[4] Abraham, Tanya. (2009).Eating with History: Ancient TradeInfluenced Cuisines of Kerala, Niyogi Books Pvt. Ltd.

[5] Banerji, Chitra. (2008).Eating India: Exploring a Nation's Cuisine, Penguin Books

[6] Singh, Yogesh. (2020).A Culinary Tour of India, Dreamtech Press

[7] Achaya, K.T. (1998). Indian Food: A Historical Companion, Oxford University Press; ( $2^{\text {nd }} \mathrm{ed}$.)

[8] Rajaiah, Ratna. (2020).Secrets of health from the Indian Kitchen, Westland Publications Private Limited

[9] Achaya, K.T. (2000). The Story of Our Food, Universities Press (India) Private Limited

[10] Namrata. Ananya. Tiwari, Divya. (2016).Indian Cuisines: Representing Indian Culture, International Research Journal of Management Sociology \& Humanity, Volume 7 Issue 9

[11] Singh, Gagandeep. (2017).The Indian Cuisine: An Exploration, International Journal of Science Technology and Management, Vol. 6, Issue No. 05, May

[12] Srinivas, Tulasi. (2011)."Exploring Indian Culture through Food" Association for Asian Studies,

[13] Mitra, Rajarshi. (2011). "Crossing the Border and Tasting the Nation: the Indian Experience in Chitrita Banerji's Eating India: Exploring a Nation's Cuisine" Rupkatha Journal on Interdisciplinary Studies in Humanities, Volume 3, Number 3 ,

[14] Sarkar, Sucharita. "Food, Memory and Everyday Transnationalism in. Chitrita Banerji's Culinary Memoirs", (2019).PostScriptum: An Interdisciplinary Journal of Literary Studies, vol. Volume IV, no. ISSN: 2456-7507

[15] Shah, Dhanishta. (2020)."Turmeric Nation - A Passage Through India's Tastes by Shylashri Shankar presents the reader with some deep food for thought" Booked for Life

[16] Prabhu, Dsouza Ruth. (2021)."In her book Turmeric Nation, Shylashri Shankar investigates how food in India interlaces with identities" Firstpost

[17] Pillai, Pooja. (2020)."Why Indian food is like a million mutinies", The Indian EXPRESS 
[18] Muthalaly, Shonali. (2020).“Turmeric Nation review: Flavours of. rich and varied culinary tradition”, The Hindu

[19] Grimes, William. (2006)."How Curry, Stirred in India, Became a World Conqueror", The New York Time

[20] Sampath Kumar, Yasaswani. (2019)."The surprising truth about Indian food",BBC

[21] Mukunda, Ghosh Lal. (2021)."The History of Indian Food Cuisine", Digital Indian

[22] Singh, Rahul. (1994)."Book review: K.T. Achaya's Indian Food - A Historical Companion", India Today

[23] Verma, Rahul. (2019).“K.T. Achaya's food history”, The Hindu

[24] Perry, Charles. (1994).“BOOK REVIEW: An Armchair Guide to the Indian Table: INDIAN FOOD: A Historical Companion", Los Angeles Times

[25] Thatipalli, Mallik. (2020).“Tanya Abraham's Eating with History unveils Kerala's wide culinary repertoire through 100- plus recipes", Firstpost

[26] Hughes, Kathryn. (2005)."The spice of life", The Guardian

[27] Basu, Anjana. (2016)."Documenting Indian food through history", Outlook traveler 